\title{
Base Plate Preheating Effect on Microstructure of 316L Stainless Steel Single Track Deposition by Directed Energy Deposition
}

\author{
Abhilash Kiran *D, Martina Koukolíková ${ }^{(D}$, Jaroslav Vavřík, Miroslav Urbánek and Jan Džugan $(\mathbb{D}$ \\ COMTES FHT a.s., Průmyslová 995, 33441 Dobřany, Czech Republic; martina.koukolikova@comtesfht.cz (M.K.); \\ jaroslav.vavrik@comtesfht.cz (J.V.); miroslav.urbanek@comtesfht.cz (M.U.); jan.dzugan@comtesfht.cz (J.D.) \\ * Correspondence: abhilash.kiran@comtesfht.cz
}

check for

updates

Citation: Kiran, A.; Koukolíková, M.; Vavř́́k, J.; Urbánek, M.; Džugan, J. Base Plate Preheating Effect on

Microstructure of 316L Stainless Steel Single Track Deposition by Directed Energy Deposition. Materials 2021, 14, 5129. https://doi.org/10.3390/ ma14185129

Academic Editor: Mariangela Lombardi

Received: 30 July 2021

Accepted: 31 August 2021

Published: 7 September 2021

Publisher's Note: MDPI stays neutral with regard to jurisdictional claims in published maps and institutional affiliations.

Copyright: (C) 2021 by the authors. Licensee MDPI, Basel, Switzerland. This article is an open access article distributed under the terms and conditions of the Creative Commons Attribution (CC BY) license (https:/ / creativecommons.org/licenses/by/ $4.0 /)$.

\begin{abstract}
The microstructural morphology in additive manufacturing (AM) has a significant influence on the building structure. High-energy concentric heat source scanning leads to rapid heating and cooling during material deposition. This results in a unique microstructure. The size and morphology of the microstructure have a strong directionality, which depends on laser power, scanning rate, melt pool fluid dynamics, and material thermal properties, etc. The grain structure significantly affects its resistance to solidification cracking and mechanical properties. Microstructure control is challenging for AM considering multiple process parameters. A preheating base plate has a significant influence on residual stress, defect-free AM structure, and it also minimizes thermal mismatch during the deposition. In the present work, a simple single track deposition experiment was designed to analyze base plate preheating on microstructure. The microstructural evolution at different preheating temperatures was studied in detail, keeping process parameters constant. The base plate was heated uniformly from an external heating source and set the stable desired temperature on the surface of the base plate before deposition. A single track was deposited on the base plate at room temperature and preheating temperatures of $200{ }^{\circ} \mathrm{C}, 300{ }^{\circ} \mathrm{C}, 400{ }^{\circ} \mathrm{C}$, and $500{ }^{\circ} \mathrm{C}$. Subsequently, the resulting microstructural morphologies were analyzed and compared. The microstructure was evaluated using electron backscattered diffraction (EBSD) imaging in the transverse and longitudinal sections. An increase in grain size area fraction was observed as the preheating temperature increased. Base plate preheating did not show influence on grain boundary misorientation. An increase in the deposition depth was noticed for higher base plate preheating temperatures. The results were convincing that grain morphology and columnar grain orientation can be tailored by base plate preheating.
\end{abstract}

Keywords: directed energy deposition; 316L stainless steel; additive manufacturing; microstructures

\section{Introduction}

Directed energy deposition (DED) is a well-known additive manufacturing (AM) process because of its unique application. The material in the form of powder/wire is supplied directly to the melt pool created by a high-energy laser/electron beam on the target surface [1-3]. This enables the depositing of the material on an irregular surface. This technique allows a combination of materials to be supplied into the melt pool. Therefore, this technique has applications like repairing engineering components, surface coating, and compositionally graded materials deposition. These applications attract vital interest to the microstructure development on a deposited material and also on the base plate. Microstructural tuning in order to tailor mechanical properties has great importance. It is evident from the extensive literature in metal AM [4-14]. Studies on grain morphology, melt pool solidification, solidification texture, the temperature gradient in the melt pool, the affect of cooling rate on morphology, and size of the microstructure are reported for AM [15-18].

The final microstructure of the deposited structure has an influence on the tensile strength and ductility. Higher tensile strength and lower ductility for DED processed 
structures appear due to a finer microstructure [19]. T. Wang et al. reported heterogeneous nucleation in the melt pool [11]. Two dominated microstructures were generated in the melt pool solidification. Epitaxial growth of equiaxed and columnar grain was noticed at the upper surface and melt pool bottom, respectively, for the single track deposition in the transverse view. Base plate grains were influenced by the hot melt pool. Grains were restructured due to rapid heating and cooling from a large temperature gradient. In the multilayer deposition process, each beneath layer acted as a heat affected zone (HAZ). A solidified layer was partially or completely remelted, which led to recrystallization, and this had an influence on the microstructure and mechanical properties of the deposited structure. Columnar grain size and orientation were the predominant factors in solid structure mechanical properties. The base plate preheating had influence on the HAZ. It was reported that the depth of the HAZ increased by an average of $400 \mu \mathrm{m}$ for a thinner base plate [19]. Repairing and surface coating application has attracted interest in the deposited and base plate grain structure [20]. Research on the surface coating application of DED has gained interest [21,22]. Controlling the HAZ depth in DED can extend these applications, including thin substrate coating. It is important to take into account the microstructural modification on the repairing component and in the surface coating applications.

Grain size and morphology in the melt pool are predominantly influenced by the temperature gradient. A grain morphology is determined by two parameters: temperature gradient within the liquid phase $(G)$ and the velocity of the solidification front $(R)$. Depending on the desired microstructure, $G$ and $R$ values can be controlled mainly by process parameters such as laser power and scanning velocity [5]. The product of $G^{*} R$ determines the cooling rate in the solidification interval. A higher cooling rate tends to the development of fine columnar structure and directionally oriented grain growth, whereas the ratio of $G$ and $R$ determines the morphology of the grains. A higher $G / R$ ratio is desired to achieve ordered columnar grains, which can be reached by cooling the base plate. The cooling of the base plate during deposition contributes to altering heat dissipation from the melt pool, which changes solidifying crystal orientation. This method results in lowered solidification cracking, whereas thermal stress is inevitable due to the higher cooling rate [23]. On the other hand, a lower $G / R$ ratio is desired to achieve columnar to equiaxed transition (CET) by homogeneous grain nucleation in the melt pool. One of the techniques to achieve a lower $G / R$ ratio is preheating the base plate. Varying process parameters to tune the microstructure alter melt pool dimensions. Grain morphology can be controlled by preheating without changing process parameters. Preheating the base plate reduces larger thermal gradients at the melt pool to the base plate/beneath layer intersection.

The cooling rate $\left(G^{*} R\right)$ while depositing a 3D solid structure varies over building direction [14]. A higher cooling rate was evident in the layers near the base plate. It was due to deposition on the base plate, which was at room temperature and acted as a faster heat sink. This might lead to different grain structures in the AM solid components. Variation of microstructure along the build direction changes the microhardness. The microhardness is higher near the base plate layer and at the top. This contributes to the fine microstructure created due to the large thermal gradient. Heat buildup in the deposited structure occurs due to continuous deposition [24]. Therefore, a higher temperature could appear during the middle section deposition. This results in the coarse grains in the middle of the structure, which yield relatively low microhardness [25]. An ideal preheating temperature for the base plate could help to develop a homogeneous microstructure in the deposited structure.

High preheating temperature appeared to be more effective for DED compared to selective laser melting (SLM) [26-28]. Corbin et al. studied the influence of Ti-6AL-4V substrate thickness on part distortion at $300{ }^{\circ} \mathrm{C}$ preheating and reported that preheating on the thin base plate was more effective [29]. Lu et al. studied different scanning strategies for preheating to reduce residual stress and distortion. At $700{ }^{\circ} \mathrm{C}$, they reported that there was lower initial distortion and residual tensile stress near the base plate. The deposition 
at $700{ }^{\circ} \mathrm{C}$ base plate preheating and $500{ }^{\circ} \mathrm{C}$ ambient temperature resulted in the final deformation and residual stress mitigation by $90.1 \%$ and $80.2 \%$, respectively [30]. Though the preheating effect on residual stress and distortion were studied in detail by several authors, a preheating effect on microstructure has not been reported to the same extent.

In the presented paper, a single track of 316L stainless steel powder was deposited on the base plate made of the same material. Subsequently, the microstructural morphology and melt pool dimensions were analyzed for different base plate preheating temperatures. The process parameters for all cases were kept constant to evaluate solely the influence of the base plate preheating on the microstructural evolution. EBSD grain mapping for a single track in transversal and longitudinal directions was investigated. A grain shape and size dependence on the base plate preheating were studied. The fusion zone (FZ) regions were evaluated. The key important factors for AM like grain size, FZ dimensions, and grain orientation for all cases were evaluated.

\section{Experimental Procedure}

\subsection{Experimental Setup}

An external preheating setup was designed for the InssTek MX-600 (InssTek, Daejeon, Korea) metallic deposition system, which is equipped with a DED process technology. A base plate holder setup was modified from standard equipment available for this machine. The heating element (Elstein, Northeim, Germany) was placed on the base plate holder using a steel frame for safety reasons. It has an operating temperature of up to $900{ }^{\circ} \mathrm{C}$ and $1000 \mathrm{~W}$ of maximum power. A block diagram of the heating element setup is depicted in Figure 1a. Fiberglass insulation was built to the height of $45 \mathrm{~mm}$ from the surface of the heating element as shown in Figure $1 \mathrm{~b}$. The base plate was placed firmly with the use of bolts. The base plate surface orientation was maintained horizontal to the height of the fiberglass insulation. The four-frame structure was designed to provide rigid support for the base plate. The frames were bolted to the base plate holder of the machine. This arrangement created a direct passage between the heating element and bottom face of the base plate surrounded by fiberglass insulation of thickness $40 \mathrm{~mm}$. The insulation helped to avoid heat loss and maintain the constant desired temperature of the base plate during the deposition.

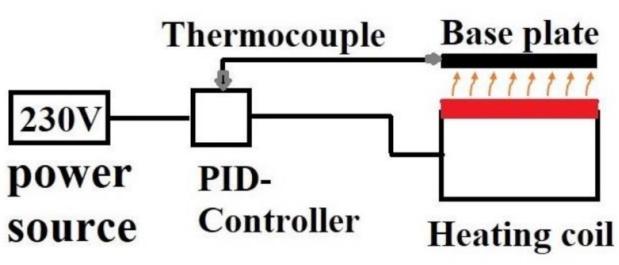

(a)

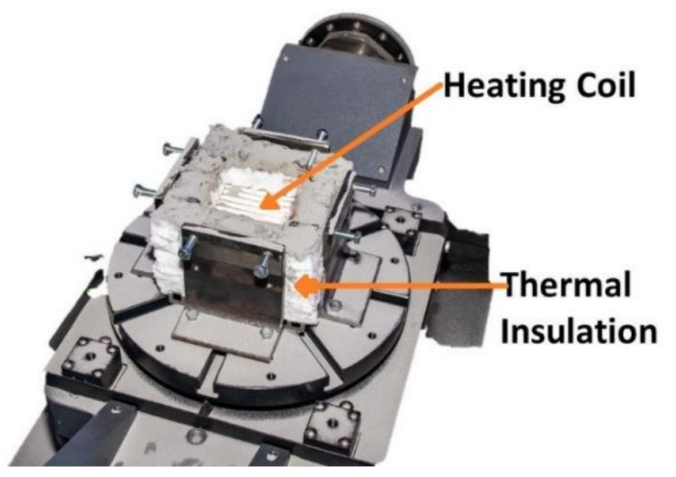

(b)

Figure 1. (a) Schematic diagram of heating system (b) Preheating setup.

InssTek MX-600 utilizes powder as the feedstock material. A laser head has multiple concentric cones, which provide passage for powder and shield gas flow. The powder is directed to the laser point contact with the base plate, where it generates the melt pool. Shielding gas at the rate of $5 \mathrm{~L} / \mathrm{min}$ was fed around the laser and powder path to separate the melt pool from the external environment to avoid oxidation. The schematic diagram of the DED working principle is illustrated in Figure 2. The melt pool is exposed to ambient temperature when the laser head moves with a defined feed rate and direction. The deposited material solidifies and forms a track as shown in Figure 3. 


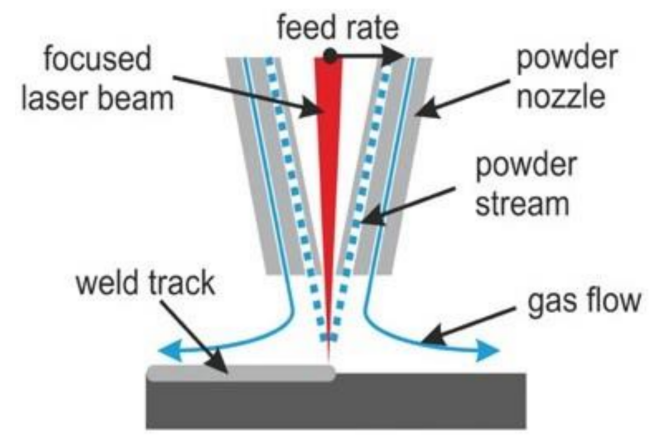

Figure 2. Schematic diagram of DED process. Reprinted from Ref. [31].

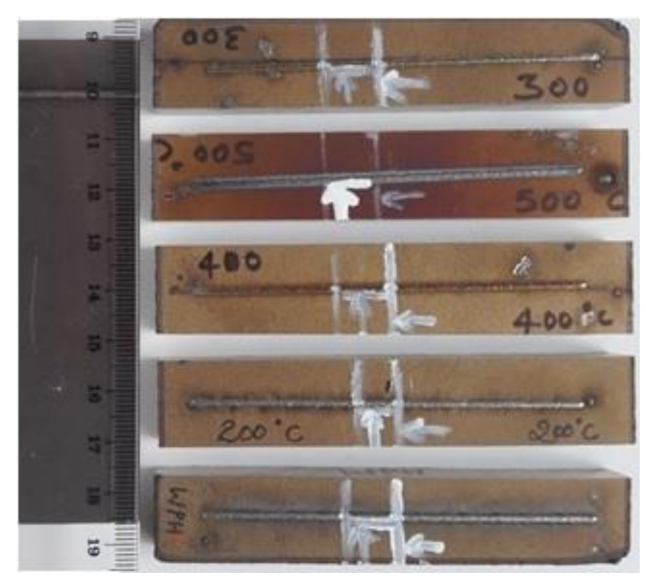

Figure 3. Single-track deposition on deferent base plate preheating temperature.

A base plate of dimensions $100 \mathrm{~mm} \times 100 \mathrm{~mm} \times 10 \mathrm{~mm}$ was heat-treated and cut into 5 pieces. This was to maintain the history of manufacturing since grain morphology in the base plate should be the same for all cases. The base plates were heated from room temperature to respective cases independently before deposition. A single-track length of $80 \mathrm{~mm}$ was deposited on the base plate of dimensions $100 \mathrm{~mm} \times 20 \mathrm{~mm} \times 10 \mathrm{~mm}$. The single track was cut in the middle along the deposition direction for transverse section examination as shown in Figure 3. Two sets for each preheating temperature case were deposited for repeatability and to evaluate the precise control on preheating conditions. One set was considered for detail investigation. The material was deposited for five different cases, namely the base plate at room temperature and preheated temperatures of $200{ }^{\circ} \mathrm{C}, 300^{\circ} \mathrm{C}, 400{ }^{\circ} \mathrm{C}$, and $500{ }^{\circ} \mathrm{C}$. The material was deposited after the base plate surface temperature was stable in respective cases. The temperature of the base plate surface was measured using a thermocouple type " $\mathrm{K}$ " [24]. The rate of temperature increase for preheating the base plate and cooling rate after deposition was monitored using real-time thermocouple data.

The DED process parameters are listed in Table 1 for all five cases. Below process parameters were provided from DED machine producer.

Table 1. Process parameters for single track DED.

\begin{tabular}{cc}
\hline Process Parameter & Value \\
\hline Laser power & $500 \mathrm{~W}$ \\
Scanning speed & $14 \mathrm{~mm} / \mathrm{s}$ \\
Laser beam diameter & $0.8 \mathrm{~mm}$ \\
Powder feed rate & $3 \mathrm{~g} / \mathrm{min}$ \\
Shielding gas and carrier gas & Argon \\
Shielding gas consumption & $5 \mathrm{~L} / \mathrm{min}$ \\
Laser standoff distance & $9 \mathrm{~mm}$ \\
\hline
\end{tabular}




\subsection{Microstructural Evaluation}

A conventional metallographic preparation involved grinding and subsequent polishing by a standard procedure performed on a Tegramin 30 (Struers GmbH, Ballerup, Denmark). The microstructures were revealed by etching in V2A solution and photographed using a light microscope Nikon Eclipse MA200 (Nikon, Tokyo, Japan) equipped with an NIS Elements 5.2 digital image processing and analysis software (Nikon, Tokyo, Japan). Detailed microstructural observation and electron backscatter diffraction (EBSD) was performed on a scanning electron microscope JEOL IT 500 HR (JEOL Ltd., Tokyo, Japan) with EDAX Hikari Super camera (EDAX LLC, Mahwah, NJ, USA) at a step size of $2.5 \mu \mathrm{m}$, analyzed area $1076 \mu \mathrm{m} \times 1080 \mu \mathrm{m}$, acceleration voltage $30 \mathrm{kV}$, scanning speed 100 diffractograms per second, and $5 \times 5$ binning. EBSD maps were processed in $75 \times$ magnification. The data acquisition, analyses, and postprocessing were performed using the software TEAM 4.5 (EDAX LLC, Mahwah, NJ, USA) and EDAX OIM Analysis ${ }^{\mathrm{TM}}$ Version 8.0 (EDAX LLC, Mahwah, NJ, USA). EBSD and optical microscope images were analyzed using ImageJ version 1.52v software (Available online: https:/ / doi.org/10.1038/nmeth.2089 (accessed on 25 July 2021)).

A typical single-track transverse section from DED for the above process parameters is illustrated in Figure 4. The deposited material showed a distinct appearance compared to the base plate region. The important regions often used in this article are marked in Figure 4. An optical microscope image shows three regions. Region-A represents the melt pool solidified area. Region-B is the HAZ on the base plate. Region-C is the base plate material. A single-track deposition from DED is comparable to the usual welding process. Region-A is called the fusion zone (FZ). In this region, molten metal was created from powder and base plate material. The microstructure in this zone was the result of the material composition and solidification rate. Region- $B$ is created due to thermal influence from the FZ. The HAZ is the region where the metallurgical process occurred in the solid-state. The HAZ is a complex region, and it is evident for several possible reactions such as grain growth, recrystallization, phase transformation, precipitate formation, and residual stress. These reactions are influenced by thermal history and material composition in this region. The solidification growth rate $(\mathrm{R})$ defines the grain morphology. Dendrites morphology depends on the temperature gradient in the melt pool. The nucleation initiates at the solid-liquid interface, which forms a solid structure within the liquid phase. Further solidification depends on the latent heat of the metal from the solidification front. The heat from the solid-liquid interface dissipates to the base plate. The intensity of the heat dissipation to the base plate reflects in the HAZ by recrystallization and grain orientation.

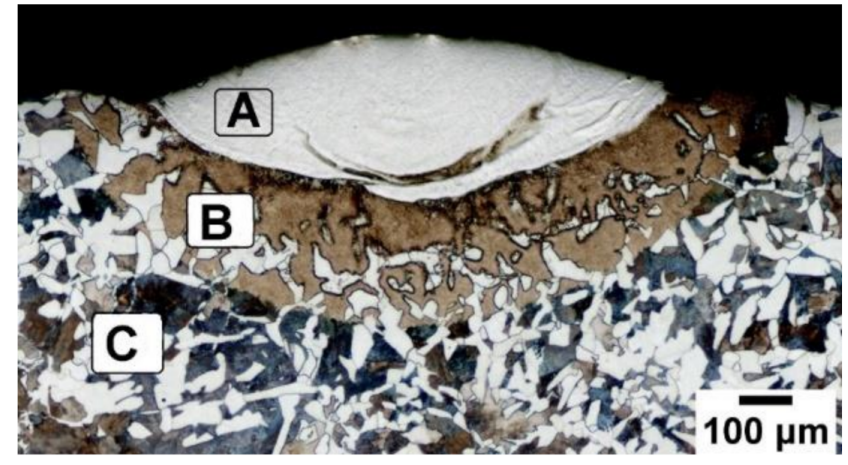

Figure 4. Transverse sectional optical image of the single-track.

The HAZ is an important region in the multilayer deposition process. During multilayer deposition for solid structure construction, every beneath layer acts as a HAZ. Important factors to determine HAZ are thermal gradient, thermal diffusivity of the material, laser power, and scanning velocity [32]. In general, the HAZ size is a result of the interplay between process parameters and material properties. 


\subsection{Material}

The solidification morphology and degree of epitaxy of microstructure growth of austenitic stainless steel 316L were relatively stable. Austenitic stainless steel 316L does not undergo phase transformation in the solid state. The change in microstructural morphology due to base plate preheating can be efficiently identified, and thus enabled us to understand the preheating influence on microstructure during the AM process. Therefore, austenitic stainless steel 316L was selected as the material for powder and base plate. The chemical compositions of the powder used for single track deposition and base plate material are listed in Table 2.

Table 2. Chemical composition (wt.\%) of austenitic stainless steel 316L.

\begin{tabular}{ccccccc}
\hline & Fe & Cr & Ni & Mo & Mn & Si \\
\hline Powder & Bal. & 17.2 & 10.4 & 2.3 & 1.3 & 0.8 \\
Base Plate & Bal. & 16.2 & 10.5 & 2.1 & 1.1 & 0.4 \\
\hline
\end{tabular}

\section{Results and Discussion}

\subsection{Microstructure Analysis}

The microstructure developed from single track deposition on the base plate at room temperature is compared to the morphological change caused by different base plate preheating temperatures.

\subsubsection{Without Preheating (WPH)}

EBSD grain mapping shown in Figure 5 depicts grain formation in the FZ region. The white line is marked at the boundaries of columnar grains separating deformed grains from the base plate.

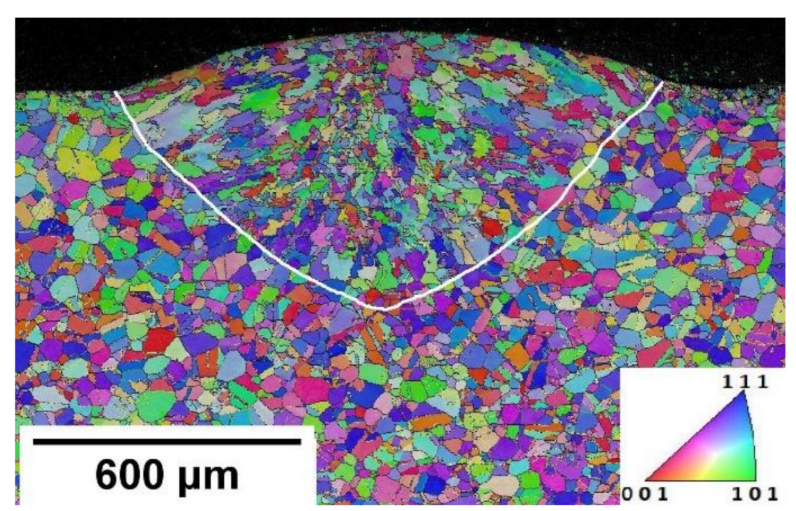

Figure 5. WPH condition EBSD map of Inverse Pole Figure (IPF) colored orientation image map with Pole Figure (PF) [001].

Fine grains were formed at the surface, which was directly exposed to the ambient temperature. The deposition chamber temperature was around $30^{\circ} \mathrm{C}$. The solidification in this region was mainly driven by the temperature gradient created due to convection heat flow from the melt pool surface to the deposition chamber. Heterogeneous nucleation could be induced by convection heat flow in the upper region and conduction in the lower portion of the melt pool to the base plate. The temperature gradient in the upper region of the melt pool could be due to forced convection. The shield gas was fed around the melt pool to protect it from oxidation. As the laser head was moving at the defined scanning speed, shielding gas was blown at the deposited material continuously as shown in Figure 2. This causes forced convection at the surface of the melt pool. This phenomenon was evident in all cases. 
The boundary formed between the melt pool and base plate in the bottom region was influenced by conduction heat flow. Grain nucleation and growth begin from the melt pool boundary progressing towards the center, known as directional solidification [33]. It is clearly evident from the transverse section image that the grain morphology in the top region is discontinued from the bottom solidification front, which is dominated by columnar grains. A similar grain morphology is reported for DED by other researchers [34,35]. The bottom region of the melt pool was in direct contact with the base plate, which was at room temperature. This led to a higher thermal gradient $(\mathrm{G})$ in the liquid melt pool, whereas a lower thermal gradient was generated away from the base plate (around the centerline of the weld pool) [36]. Thus, coarse grains formation at the center of the weld line can be noticed in Figure 6.

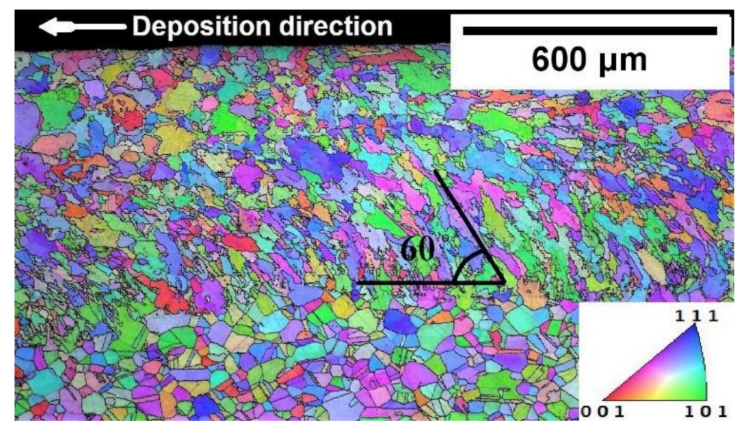

Figure 6. EBSD orientation map for longitudinal section deposited WPH with IPF [001].

Grains in the bottom region of the FZ are prone to incline towards deposition direction as shown in the EBSD longitudinal section image in Figure 6. It is well known that face centered cubic (FCC) crystals are most preferred to grow in $<100>$ direction. Grains preferred to grow in $<100>$ crystallographic direction from the base plate that is parallel to the local heat flow direction. Temperature gradient at the interface of the melt pool and base plate influence has a large impact on grain morphology. Therefore, grain morphology and temperature gradient could be controlled by the base plate preheating keeping all process parameters constant.

\subsubsection{Preheating Conditions}

The EBSD analysis provided information on the development of the microstructure of individual base plate preheating temperatures. The color IPF maps represent random grain orientations along cross-sections for all states (perpendicular to laser track) in Figure 7. All images show the same trend of grain morphology similar to the WPH case presented in Figure 5. The bottom region of the FZ is dominated by columnar grains. In contrast, the topmost region of the FZ is dominated by fine grains. Grain growth and rearrangement, as observed on the IPF and PF shown in Figure $7 \mathrm{~b}, \mathrm{~g}$, respectively, proved that from base plate preheating temperature $300{ }^{\circ} \mathrm{C}$ there is an increase in the grain size fraction area with the increasing temperature.

The pole figures, which enable the representation of the preferred orientation (texture) in the analyzed material (Figure 7), proved that no strong texture was formed during single track deposition at a given base plate preheating temperature.

The elongated columnar grains perpendicular to the solidification front can be observed for all cases. This is dependent on the value of temperature gradient $(G)$ and solidification rate $(\mathrm{R})$ within the melt pool [33]. The melt pool creates a curved solidliquid front for solidification, and the melt pool dimensions are dynamic. The $G$ and $R$ values change constantly from the base plate intersection to the centerline of the melt pool [37]. That creates competition for columnar grain growth. The columnar grain growth towards the centerline of the melt pool reflects the heat dissipation direction. The base plate preheating enlarges the depth of laser penetration. Interestingly, the preheating $500{ }^{\circ} \mathrm{C}$ condition had consistent columnar grain orientation and parabolic shape, shown in Figure $7 \mathrm{~d}$ 
(parabolic shape can also be seen clearly in optical microscope image in Figure 10a). Solidification of the two solidification fronts from the sides of the melt pool boundary developed towards the centerline (vertical path of the laser penetration). This could be a result of the deeper laser penetration due to preheating, as remelting depth depends on the energy input [38].

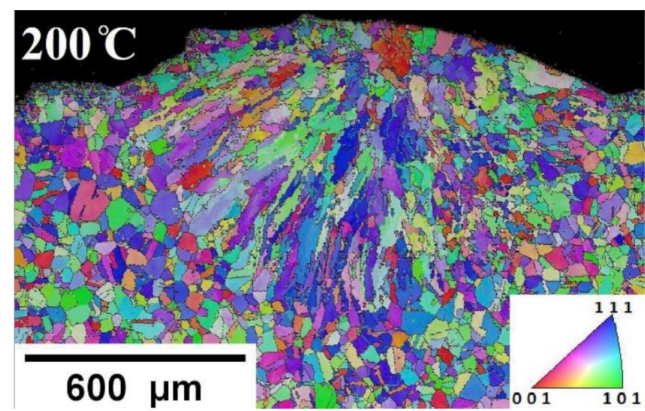

(a)

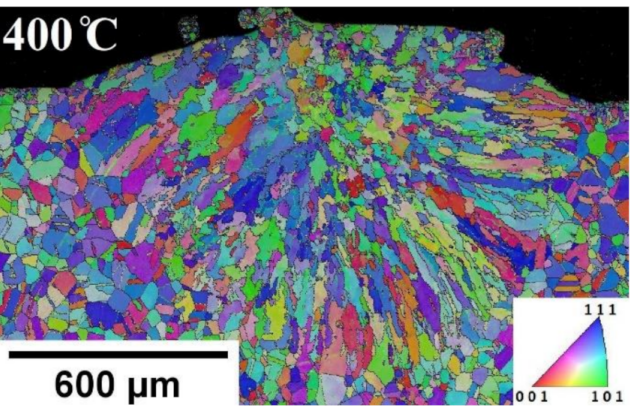

(c)

(e)
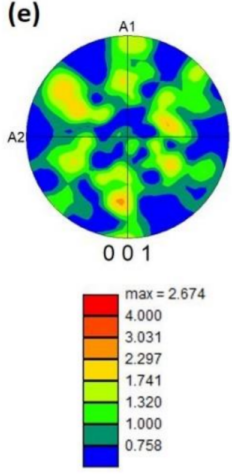

WPH (f)
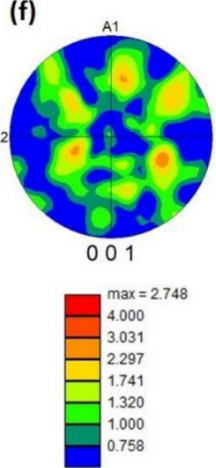

$200^{\circ} \mathrm{C}$ (g)
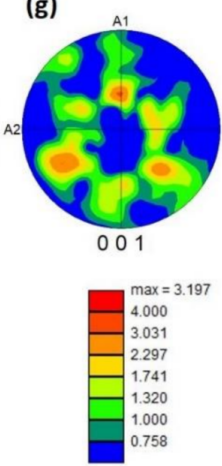

$300^{\circ} \mathrm{C}$

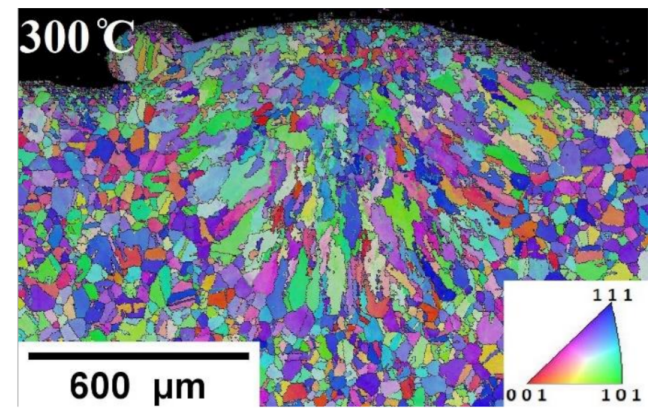

(b)

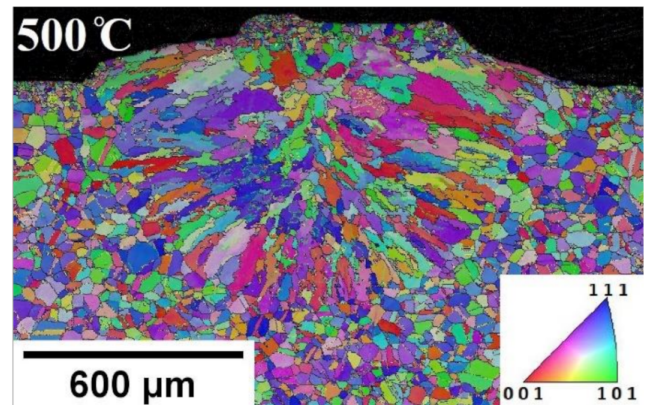

(d)

(h)
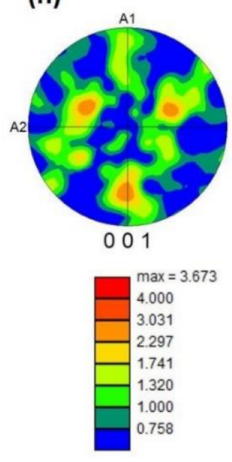

$400^{\circ} \mathrm{C}$ (i)

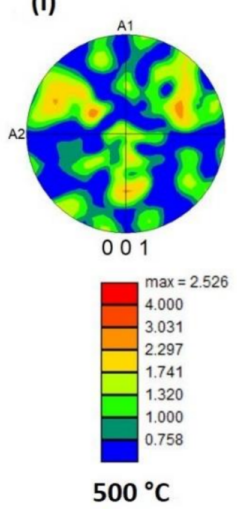

Figure 7. EBSD inverse pole figure maps for preheating base plate single track transverse section. (a) IPF-200 ${ }^{\circ} \mathrm{C}$ (b) IPF- $300^{\circ} \mathrm{C}$ (c) IPF $-400^{\circ} \mathrm{C}$ (d) IPF- $500^{\circ} \mathrm{C}$ and pole figures (e) WPH (f) $200^{\circ} \mathrm{C}$ (g) $300{ }^{\circ} \mathrm{C}$ (h) $400{ }^{\circ} \mathrm{C}$ (i) $500{ }^{\circ} \mathrm{C}$.

It is important to notice that as the preheating temperature increases, the area fraction of coarse grains also increases, which is evident from the grains size calculation shown in Figure 8 . The grain size distribution and misorientation angle were calculated, taking into account only the FZ regions (marked in Figure 5) from the respective IPF. Minimum and maximum grain size ranges lied between $6 \mu \mathrm{m}$ and $94 \mu \mathrm{m}$ for the WPH case, as depicted in Figure 8a. The base plate at room temperature acted as a sink, and it facilitated a high rate of heat flow from the melt pool. Interestingly, the grain size range did not vary much for $300{ }^{\circ} \mathrm{C}$ and $400{ }^{\circ} \mathrm{C}$ preheating conditions. The range fell largely between $7 \mu \mathrm{m}$ and around $125 \mu \mathrm{m}$. The preheating at $200{ }^{\circ} \mathrm{C}$ resulted in a larger area fraction of the finer grains in the range between $16 \mu \mathrm{m}$ and $66 \mu \mathrm{m}$. Based on the IPF and PF observation, the area fraction of large grains increased from preheating $300{ }^{\circ} \mathrm{C}$, which can be noticed in 
the grain size distribution data illustrated in Figure 8c, whereas a significant amount of area occupied by large grains over $100 \mu \mathrm{m}$ for preheating at $500{ }^{\circ} \mathrm{C}$ is depicted in Figure $8 \mathrm{e}$. The larger grain size in the range from $131 \mu \mathrm{m}$ to $145 \mu \mathrm{m}$ with considerable area share can be noticed. This indicates that the preheating base plate has an influence on coarsening grains and extending area fraction for larger grains. A large area fraction of coarser grains was calculated for the $500{ }^{\circ} \mathrm{C}$ base plate preheating case. A large area fraction of coarse grains indicates the holding of heat due to preheating of the base plate. This could reduce the thermal mismatch between the melt pool generated from a high-energy concentric heat source and the base plate. Thus, preheating could minimize structural distortion while separating from the base plate. Low-angle grain boundaries $\left(\mathrm{LAGB}<5^{\circ}\right.$ ) occupied a large number fraction (between 0.6 and 0.73 ) for all cases. A relatively lower number fraction (maximum of 0.046) for high-angle grain boundaries (HAGB) is calculated for all cases. It is evident that preheating the base plate does not have an influence on grain boundary misorientation for single track deposition. Similar results are reported for 316L stainless steel fabricated via direct laser deposition (DLD), and an increase in the high-angle boundaries $\left(60^{\circ}\right)$ was observed for the heat-treated sample [39]. In contrast, SLM-processed $\mathrm{Ti}-45 \mathrm{Al}-2 \mathrm{Cr}-5 \mathrm{Nb}$ alloy preheating results in HAGB dominated microstructure [16].

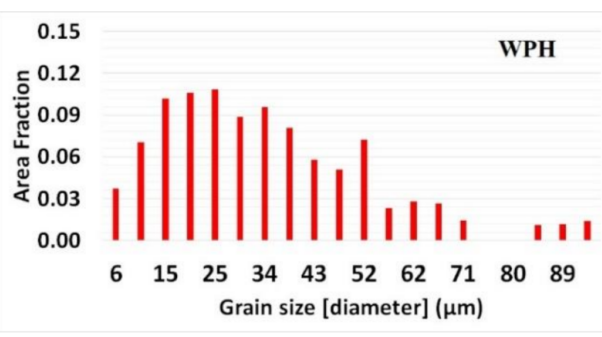

(a)

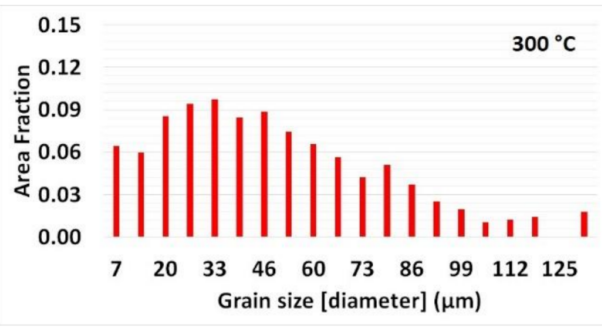

(c)

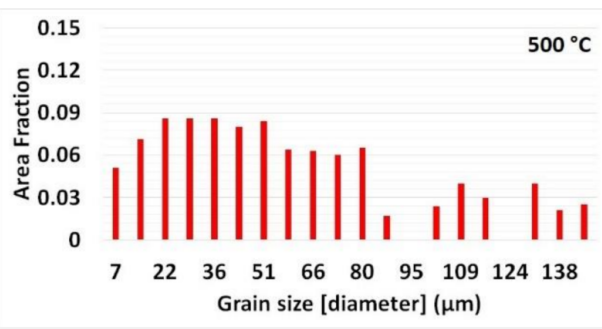

(e)

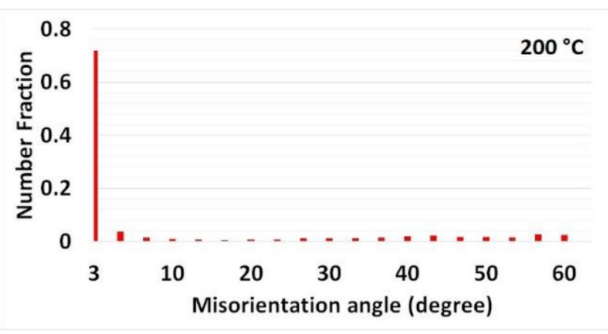

(g)

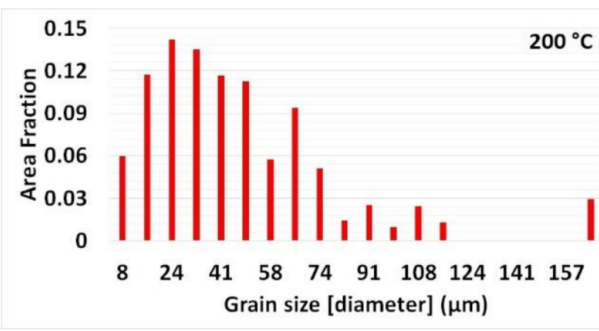

(b)

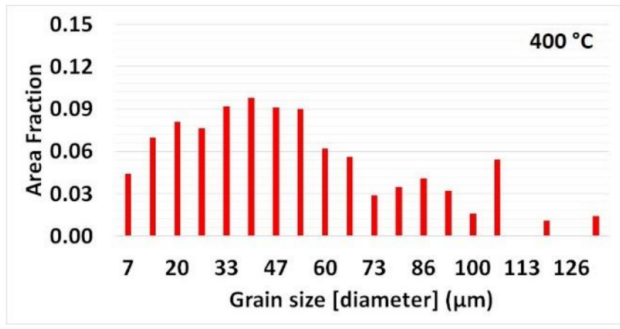

(d)

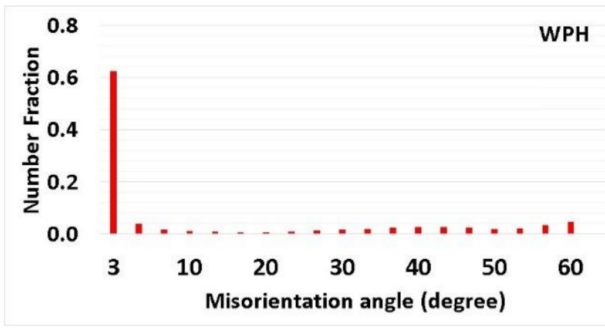

(f)

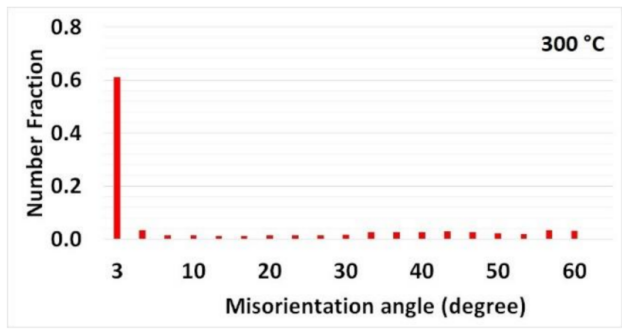

(h)

Figure 8. Cont. 


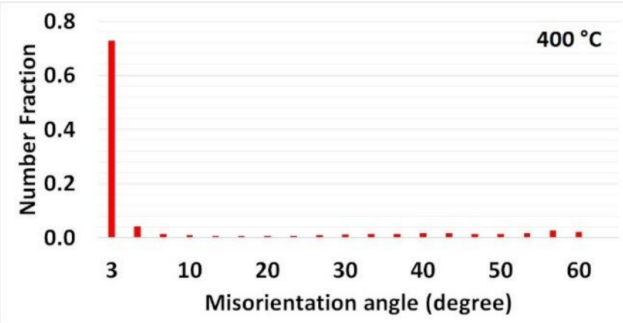

(i)

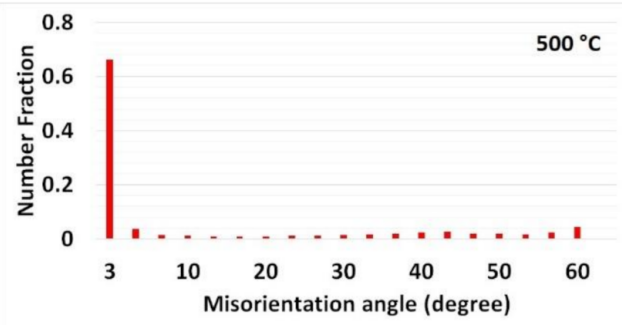

(j)

Figure 8. Grain size distribution data (a) WPH (b) $200{ }^{\circ} \mathrm{C}$ (c) $300{ }^{\circ} \mathrm{C}$ (d) $400{ }^{\circ} \mathrm{C}$ (e) $500{ }^{\circ} \mathrm{C}$ and grain boundary misorientation data (f) WPH (g) $200{ }^{\circ} \mathrm{C}$ (h) $300{ }^{\circ} \mathrm{C}(\mathbf{i}) 400{ }^{\circ} \mathrm{C}(\mathbf{j}) 500{ }^{\circ} \mathrm{C}$.

A shift in average area fraction can be noticed between WPH and $200{ }^{\circ} \mathrm{C}$ preheating, depicted in Figure 9. Further, for $300^{\circ} \mathrm{C}$ and $400{ }^{\circ} \mathrm{C}$ preheating conditions, the average area fraction was nearly the same. However, a noticeable increase for $500^{\circ} \mathrm{C}$ preheating conditions was observed. Preheating temperature has a negative impact on the cooling rate $(T=G \times R)$ [16]. Preheating temperature increased results in a reduced temperature gradient from the melt pool to the base plate. A negative impact on cooling rate during base plate preheating assisted in coarsening grains for large area fractions.

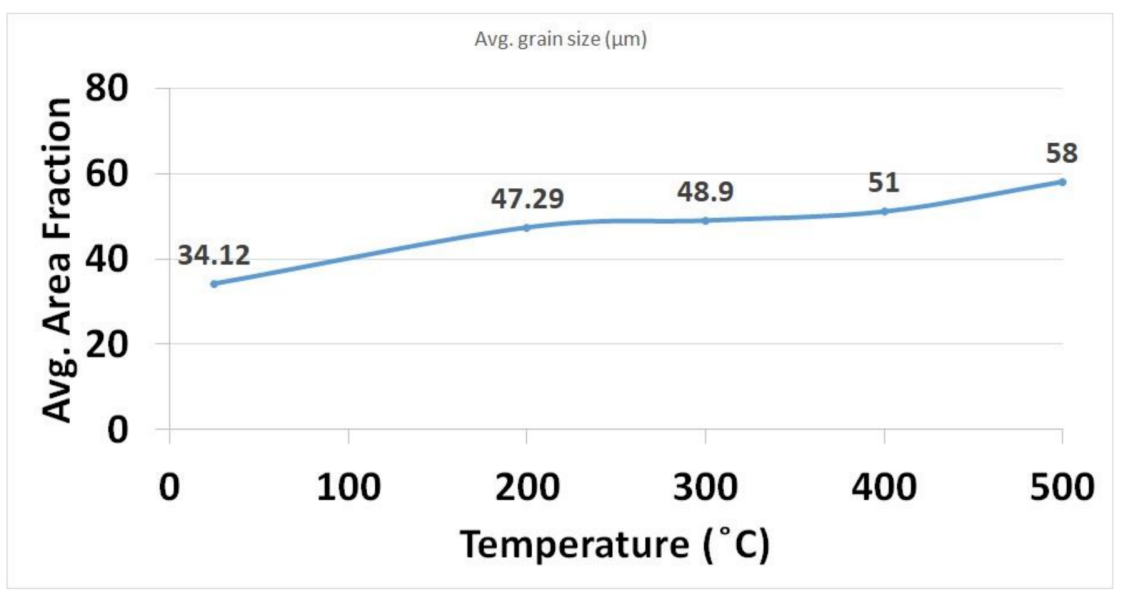

Figure 9. Average grain size plot for different base plate preheating temperature.

\subsubsection{Melt Pool Dimensions}

The width of the deposited material was measured using the optical microscope image, shown in Figure 10a, and height was measured for the longitudinal section, shown in Figure 10c.

The width of deposition almost remained constant for all cases, as shown in Figure 10b. A slight increase in width can be noticed for preheating temperature $400{ }^{\circ} \mathrm{C}$. The results indicate a minor influence of preheating on the width of the deposit. The width of deposition is a major factor for welding. The width of the weld pool determines the strength of the joint, whereas in AM, multiple tracks are deposited with overlap on the subsequent track. The height of the melt pool and its consistency are important to determine the percentage of mixing materials and influence on the base plate material. The height of deposition was measured from the respective longitudinal section. The sections where minimum height measured was marked in blue indication and maximum height is shown in red color are presented in Figure 10c. Deposition height linearly increased as the preheating temperature increased. The base plate preheating enlarged the depth of laser penetration, which resulted in increasing the height of FZ. The height increased from preheating temperature $300^{\circ} \mathrm{C}$. More specifically, the largest height was reported for preheating $500{ }^{\circ} \mathrm{C}$. The difference in minimum and maximum height reported from preheating temperatures $300{ }^{\circ} \mathrm{C}$ and above 
was nearly the same. Comparatively, the preheating $500{ }^{\circ} \mathrm{C}$ height of deposition appeared to be more uniform, as shown in Figure 10c.

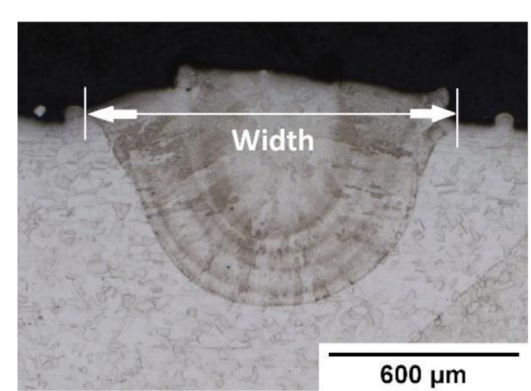

(a)

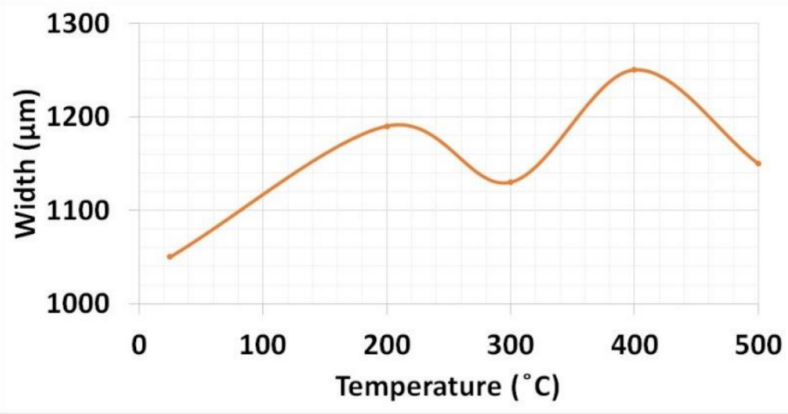

(b)

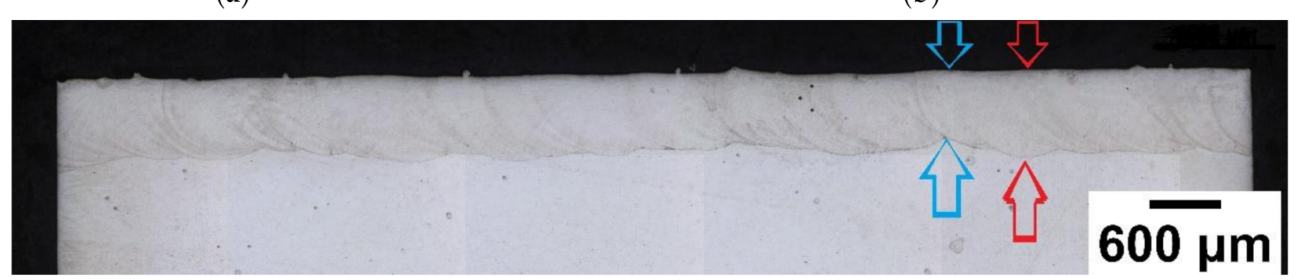

(c)

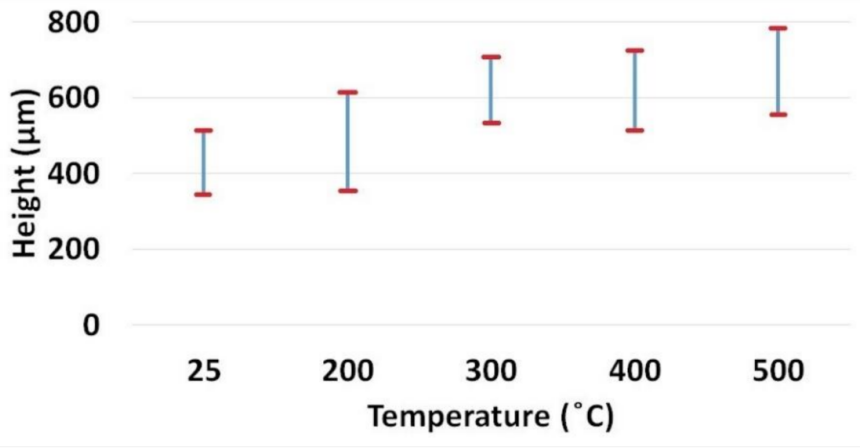

(d)

Figure 10. (a) Width measurement in the preheating $500{ }^{\circ} \mathrm{C}$ optical microscope image (b) Width plot for different base plate preheating temperature (c) Height measurement in the preheating $500{ }^{\circ} \mathrm{C}$ (d) Height measurement plot.

\subsubsection{Longitudinal Section}

The single track deposition was cut along the deposition direction, which provides a perpendicular view on a grain morphology to the deposition direction. The observations made in both transversal and longitudinal sections help to analyze grain formation in three dimensions.

The longitudinal view reveals grains that are inclined towards the deposition direction in the top region of the FZ. An enlarged grains growth, which was parallel to deposition direction, can be seen for preheating $300^{\circ} \mathrm{C}$ and $400^{\circ} \mathrm{C}$. The preheating $500{ }^{\circ} \mathrm{C}$ longitudinal section was characterized by coarser equiaxed grains in the top region, as shown in Figure 11d.

The grains were oriented at an angle towards the deposition direction in the lower region of the FZ. It can be seen from Figure 11 that columnar grains were inclined towards the deposition direction in all cases. The grains were oriented around $60 \pm 5^{\circ}$ for WPH (Figure 6) and preheating $200{ }^{\circ} \mathrm{C}$ (Figure 11a). Typically, the grains orientate towards the moving melt pool in DED. The grain orientation around $60 \pm 5^{\circ}$ has been reported for unidirectional laser scanning in the multilayer deposition for DED [40-42]. 


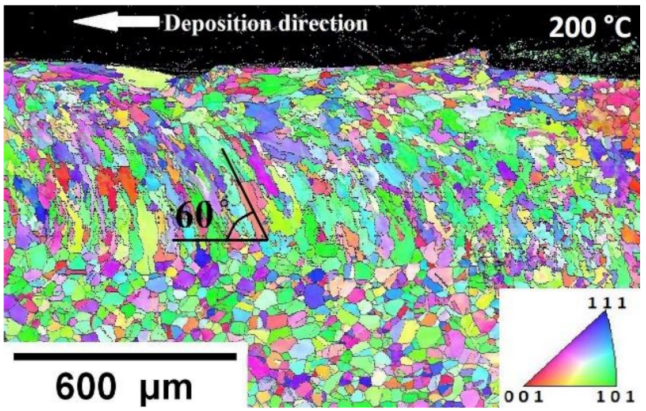

(a)

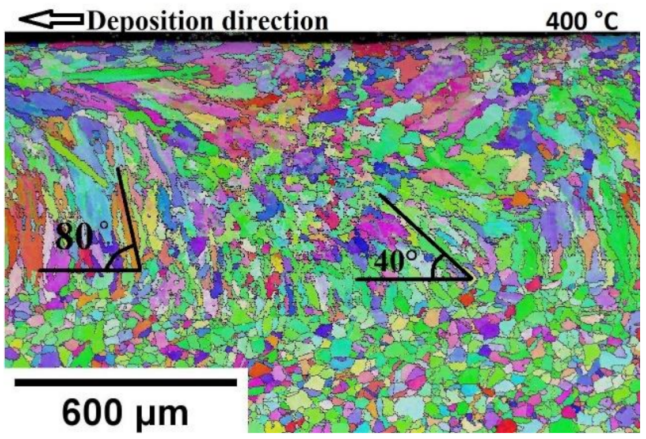

(c)

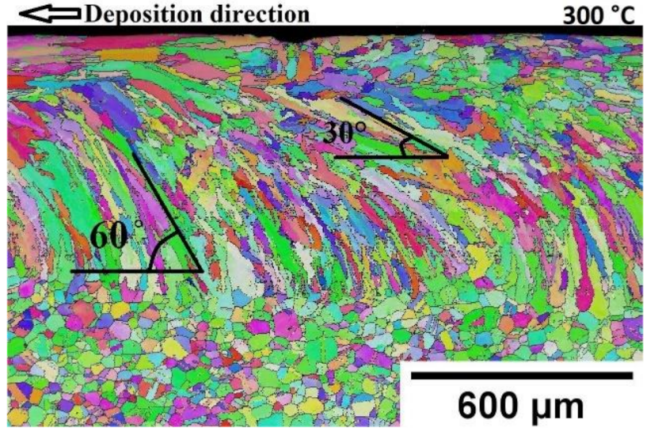

(b)

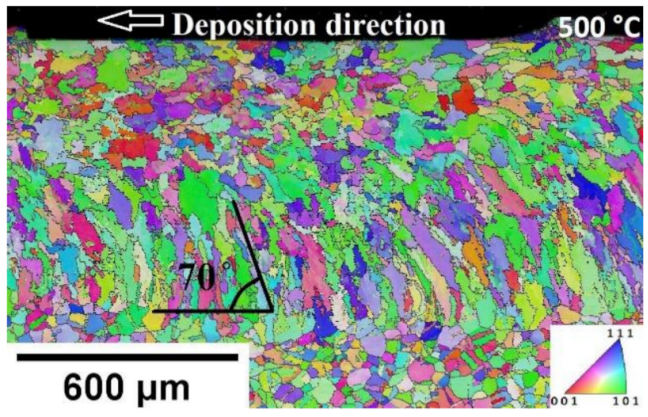

(d)

Figure 11. EBSD maps for preheating base plate single track longitudinal section. IPF colored orientation image map of preheating temperature (a) $200{ }^{\circ} \mathrm{C}$ (b) $300{ }^{\circ} \mathrm{C}$ (c) $400{ }^{\circ} \mathrm{C}$ (d) $500{ }^{\circ} \mathrm{C}$.

It is worth noting that elongated columnar grains were developed for the preheating $300{ }^{\circ} \mathrm{C}$ and $400{ }^{\circ} \mathrm{C}$, whereas $500{ }^{\circ} \mathrm{C}$ preheating assisted to develop a homogeneous microstructure. The longitudinal section of preheating $300^{\circ} \mathrm{C}$ and $400^{\circ} \mathrm{C}$ exhibited inhomogeneous columnar grains orientation. The grain orientation varied between $30^{\circ}$ to $60^{\circ}$ for preheating $300^{\circ} \mathrm{C}$ and $40^{\circ}$ to $80^{\circ}$ for preheating $400{ }^{\circ} \mathrm{C}$. Notably, at $500{ }^{\circ} \mathrm{C}$ preheating, the majority of columnar grains orientated at $70^{\circ}$.

\section{Conclusions}

Based on the results of microstructural analysis, it is evident that during single track deposition, the preheating of the base plate influences microstructure morphology. For preheating at $500^{\circ} \mathrm{C}$, an average area fraction of grain size distribution was almost doubled compared to the base plate without preheating. Base plate preheating for austenite 316L material single track deposition did not show any clear influence on the development of strong texture and a grain boundary misorientation angle.

The width of deposition was relatively stable for all cases. The height of deposition increased with the increase in preheating temperature. This indicates possible influence during a multilayer deposition where the previous layer acts as a deposition platform. The columnar grains orientation in the longitudinal section was observed to be inhomogeneous for base plate preheating conditions of $300{ }^{\circ} \mathrm{C}$ and $400{ }^{\circ} \mathrm{C}$. At $500{ }^{\circ} \mathrm{C}$ preheating conditions, most of the columnar grains had an orientation angle around $70^{\circ}$. Thus, the preheating condition at $500{ }^{\circ} \mathrm{C}$ showed predominant effect on grain size and orientation. Varying the substrate preheating temperature proved the possibility to tailor the grains' size and orientation. These results are crucial to understanding preheating effect on multi-layer deposition. Single-track deposition results can serve as a reference to measure the degree of influence during the base plate preheating at $50{ }^{\circ} \mathrm{C}$ for multilayer deposition. A significant transformation at $500{ }^{\circ} \mathrm{C}$ base plate preheating for single track deposition indicates the need to evaluate base plate preheating effect on microstructure, mechanical properties, and residual stress during multilayer solid structure deposition. 
Author Contributions: Conceptualization, A.K.; Investigation, M.K. and J.V.; writing-original draft preparation, A.K.; Writing-review \& editing, M.U. and J.D. All authors have read and agreed to the published version of the manuscript.

Funding: The paper was supported from ERDF Pre-Application Research of Functionally Graduated Materials by Additive Technologies, No. CZ.02.1.01/0.0/0.0/17_048/0007350.

Institutional Review Board Statement: Not applicable.

Informed Consent Statement: Not applicable.

Data Availability Statement: Data available in a publicly accessible repository.

Conflicts of Interest: The authors declare no conflict of interest.

\section{References}

1. Kiran, A.; Hodek, J.; Vavř́ík, J.; Urbánek, M.; Džugan, J. Numerical Simulation Development and Computational Optimization for Directed Energy Deposition Additive Manufacturing Process. Materials 2020, 13, 2666. [CrossRef]

2. Froend, M.; Ventzke, V.; Kashaev, N.; Klusemann, B.; Enz, J. Thermal analysis of wire-based direct energy deposition of Al-Mg using different laser irradiances. Addit. Manuf. 2019, 29, 100800. [CrossRef]

3. Sing, S.; Tey, C.; Tan, J.; Huang, S.; Yeong, W.Y. 2-3D printing of metals in rapid prototyping of biomaterials: Techniques in additive manufacturing. In Rapid Prototyp. Biomater, 2nd ed.; Narayan, R., Ed.; Woodhead Publishing: Sawston, UK, 2020; pp. 17-40. [CrossRef]

4. Saboori, A.; Aversa, A.; Marchese, G.; Biamino, S.; Lombardi, M.; Fino, P. Microstructure and Mechanical Properties of AISI 316L Produced by Directed Energy Deposition-Based Additive Manufacturing: A Review. Appl. Sci. 2020, 10, 3310. [CrossRef]

5. Bertoli, U.S.; MacDonald, B.; Schoenung, J.M. Stability of cellular microstructure in laser powder bed fusion of 316L stainless steel. Mater. Sci. Eng. A 2019, 739, 109-117. [CrossRef]

6. Raghavan, N.; Dehoff, R.; Pannala, S.; Simunovic, S.; Kirka, M.; Turner, J.; Carlson, N.; Babu, S. Numerical modeling of heat-transfer and the influence of process parameters on tailoring the grain morphology of IN718 in electron beam additive manufacturing. Acta Mater. 2016, 112, 303-314. [CrossRef]

7. Mertens, R.; Vrancken, B.; Holmstock, N.; Kinds, Y.; Kruth, J.-P.; Van Humbeeck, J. Influence of Powder Bed Preheating on Microstructure and Mechanical Properties of H13 Tool Steel SLM Parts. Phys. Procedia 2016, 83, 882-890. [CrossRef]

8. Wei, H.; Elmer, J.; DebRoy, T. Origin of grain orientation during solidification of an aluminum alloy. Acta Mater. 2016, 115, 123-131. [CrossRef]

9. Song, X.; Xie, M.; Hofmann, F.; Illston, T.; Connolley, T.; Reinhard, C.T.; Atwood, R.C.; Connor, L.D.; Drakopoulos, M.; Frampton, L.; et al. Residual stresses and microstructure in Powder Bed Direct Laser Deposition (PB DLD) samples. Int. J. Mater. Form. 2015, 8, 245-254. [CrossRef]

10. Liu, F.; Lin, X.; Yang, G.; Song, M.; Chen, J.; Huang, W. Microstructure and residual stress of laser rapid formed Inconel 718 nickel-base superalloy. Opt. Laser Technol. 2011, 43, 208-213. [CrossRef]

11. Wang, T.; Zhu, Y.; Zhang, S.; Tang, H.; Wang, H. Grain morphology evolution behavior of titanium alloy components during laser melting deposition additive manufacturing. J. Alloys Compd. 2015, 632, 505-513. [CrossRef]

12. Wang, L.; Wang, N. Effect of substrate orientation on the formation of equiaxed stray grains in laser surface remelted single crystal superalloys: Experimental investigation. Acta Mater. 2016, 104, 250-258. [CrossRef]

13. Wei, H.; Mazumder, J.; Debroy, T. Evolution of solidification texture during additive manufacturing. Sci. Rep. 2015, 5, 16446. [CrossRef]

14. Park, J.; Kim, J.-Y.; Ji, I.; Lee, S.H. Numerical and Experimental Investigations of Laser Metal Deposition (LMD) Using STS 316L. Appl. Sci. 2020, 10, 4874. [CrossRef]

15. Herzog, D.; Seyda, V.; Wycisk, E.; Emmelmann, C. Additive manufacturing of metals. Acta Mater. 2016, 117, 371-392. [CrossRef]

16. Li, W.; Liu, J.; Zhou, Y.; Wen, S.; Wei, Q.; Yan, C.; Shi, Y. Effect of substrate preheating on the texture, phase and nanohardness of a $\mathrm{Ti}-45 \mathrm{Al}-2 \mathrm{Cr}-5 \mathrm{Nb}$ alloy processed by selective laser melting. Scr. Mater. 2016, 118, 13-18. [CrossRef]

17. Jia, Q.; Gu, D. Selective laser melting additive manufacturing of Inconel 718 superalloy parts: Densification, microstructure and properties. J. Alloys Compd. 2014, 585, 713-721. [CrossRef]

18. Kistler, N.A.; Corbin, D.J.; Nassar, A.R.; Reutzel, E.; Beese, A.M. Effect of processing conditions on the microstructure, porosity, and mechanical properties of Ti-6Al-4V repair fabricated by directed energy deposition. J. Mater. Process. Technol. 2019, 264, 172-181. [CrossRef]

19. Beese, A.M.; Carroll, B.E. Review of Mechanical Properties of Ti-6Al-4V Made by Laser-Based Additive Manufacturing Using Powder Feedstock. JOM 2015, 68, 724-734. [CrossRef]

20. Saboori, A.; Aversa, A.; Marchese, G.; Biamino, S.; Lombardi, M.; Fino, P. Application of Directed Energy Deposition-Based Additive Manufacturing in Repair. Appl. Sci. 2019, 9, 3316. [CrossRef]

21. Vavř́k , J.; Hrbáčková, T.; Salvetr, P.; Brázda, M. Stellite coating deposited by directed energy deposition. In Proceedings of the 29th International Conference on Metallurgy and Materials, Brno, Czech Republic, 20-22 May 2020; pp. 822-826. [CrossRef] 
22. Vavrik, J.; Salvetr, P.; Urbanek, M.; Hodek, J.; Brazda, M.; Bily, M. Microstructural observations of am deposited 15-5ph-stellite sample. MM Sci. J. 2021, 2021, 4316-4321. [CrossRef]

23. Chen, Y.; Lu, F.; Zhang, K.; Nie, P.; Hosseini, S.R.E.; Feng, K.; Li, Z. Dendritic microstructure and hot cracking of laser additive manufactured Inconel 718 under improved base cooling. J. Alloys Compd. 2016, 670, 312-321. [CrossRef]

24. Kiran, A.; Hodek, J.; Vavřík, J.; Lukáš, O.; Urbánek, M. Distortion modelling of steel 316L symmetric base plate for additive manufacturing process and experimental calibration. In Proceedings of the 29th International Conference on Metallurgy and Materials, Brno, Czech Republic, 20-22 May 2020; pp. 862-867. [CrossRef]

25. Thompson, S.M.; Bian, L.; Shamsaei, N.; Yadollahi, A. An overview of Direct Laser Deposition for additive manufacturing; Part I: Transport phenomena, modeling and diagnostics. Addit. Manuf. 2015, 8, 36-62. [CrossRef]

26. Kempen, K.; Thijs, L.; Vrancken, B.; Buls, S.; Van Humbeeck, J.; Kruth, J.P. Producing Crack-Free, High Density M2 HSS Parts by Selective Laser Melting: Pre-Heating the Baseplate. In Proceedings of the 24th International SFF Symposium-An Additive Manufacturing Conference, Austin, TX, USA, 12-14 August 2013. Available online: https:/ /imo.libis.be/primo-explore/fulldisplay? docid=LIRIAS1572877\&context=L\&vid=Lirias\&search_scope=Lirias\&tab=default_tab\&lang=en_US\&fromSitemap=1 (accessed on 25 July 2021).

27. Buchbinder, D.; Meiners, W.; Pirch, N.; Wissenbach, K.; Schrage, J. Investigation on reducing distortion by preheating during manufacture of aluminum components using selective laser melting. J. Laser Appl. 2014, 26, 012004. [CrossRef]

28. Motibane, L.P.; Tshabalala, L.C.; Mathe, N.R.; Hoosain, S.; Knutsen, R.D. Effect of powder bed preheating on distortion and mechanical properties in high speed selective laser melting. IOP Conf. Ser. Mater. Sci. Eng. 2019, 655, 012026. [CrossRef]

29. Corbin, D.J.; Nassar, A.R.; Reutzel, E.; Beese, A.M.; Michaleris, P. Effect of Substrate Thickness and Preheating on the Distortion of Laser Deposited Ti-6Al-4V. J. Manuf. Sci. Eng. 2018, 140, 061009. [CrossRef]

30. Lu, X.; Lin, X.; Chiumenti, M.; Cervera, M.; Hu, Y.; Ji, X.; Ma, L.; Yang, H.; Huang, W. Residual stress and distortion of rectangular and S-shaped Ti-6Al-4V parts by Directed Energy Deposition: Modelling and experimental calibration. Addit. Manuf. 2019, 26, 166-179. [CrossRef]

31. Junker, D.; Hentschel, O.; Schmidt, M.; Merklein, M. Qualification of laser based additive production for manufacturing of forging Tools. MATEC Web Conf. 2015, 21, 08010. [CrossRef]

32. Welding Metallurgy Principles; John Wiley \& Sons, Ltd.: Hoboken, NJ, USA, 2015; pp. 9-83. [CrossRef]

33. Kurz, W.; Fisher, D.J. Fundamentals of Solidification, 4th ed.; Trans Tech Publications, Ltd.: Zurich, Switzerland, 1998.

34. Segerstark, A.; Andersson, J.; Svensson, L.-E. Investigation of laser metal deposited Alloy 718 onto an EN 1.4401 stainless steel substrate. Opt. Laser Technol. 2017, 97, 144-153. [CrossRef]

35. Sreekanth, S.; Ghassemali, E.; Hurtig, K.; Joshi, S.; Andersson, J. Effect of Direct Energy Deposition Process Parameters on Single-Track Deposits of Alloy 718. Metals 2020, 10, 96. [CrossRef]

36. Trivedi, R.; David, S.A.; Eshelman, M.A.; Vitek, J.M.; Babu, S.S.; Hong, T.; Debroy, T. In situ observations of weld pool solidification using transparent metal-analog systems. J. Appl. Phys. 2003, 93, 4885. [CrossRef]

37. DuPont, J.N. Fundamentals of Weld Solidification; Lienert, T., Siewert, T., Babu, S., Acoff, V., Eds.; ASM International: Almere, The Netherlands, 2011. [CrossRef]

38. Yadroitsev, I.; Krakhmalev, P.; Yadroitsava, I.; Johansson, S.; Smurov, I. Energy input effect on morphology and microstructure of selective laser melting single track from metallic powder. J. Mater. Process. Technol. 2013, 213, 606-613. [CrossRef]

39. Yadollahi, A.; Shamsaei, N.; Thompson, S.M.; Seely, D.W. Effects of process time interval and heat treatment on the mechanical and microstructural properties of direct laser deposited 316L stainless steel. Mater. Sci. Eng. A 2015, 644, 171-183. [CrossRef]

40. Dinda, G.; Dasgupta, A.; Mazumder, J. Texture control during laser deposition of nickel-based superalloy. Scr. Mater. 2012, 67, 503-506. [CrossRef]

41. Dinda, G.; Dasgupta, A.; Mazumder, J. Evolution of microstructure in laser deposited Al-11.28\%Si alloy. Surf. Coat. Technol. 2012, 206, 2152-2160. [CrossRef]

42. DebRoy, T.; Wei, H.L.; Zuback, J.S.; Mukherjee, T.; Elmer, J.W.; Milewski, J.O.; Beese, A.M.; Wilson-Heid, A.; De, A.; Zhang, W. Additive manufacturing of metallic components-Process, structure and properties. Prog. Mater. Sci. 2018, 92, 112-224. [CrossRef] 